\title{
Investigation on the Textural Properties Tuning of Ordered Mesoporous Carbons with an Excellent Electrochemical Performance
}

\author{
Pavuluri Srinivasu \\ International Center for Young Scientists, International Center for Materials Nanoarchitectonics, \\ National Institute for Materials Science, 1-1 Namiki, Ibaraki, Tsukuba 305-0044, Japan \\ Correspondence should be addressed to Pavuluri Srinivasu, pavuluri.srini@gmail.com
}

Received 16 June 2011; Accepted 25 July 2011

Academic Editor: Surya Prakash Singh

Copyright () 2011 Pavuluri Srinivasu. This is an open access article distributed under the Creative Commons Attribution License, which permits unrestricted use, distribution, and reproduction in any medium, provided the original work is properly cited.

A synthetic method to produce mesoporous carbons with tunable textural properties and ordered pore structure has been developed by changing sucrose to water ratio. The specific surface area of $1437 \mathrm{~m}^{2} / \mathrm{g}$ with pore volume of $1.4 \mathrm{~cm}^{3} / \mathrm{g}$ and porosity of mesopores centered at around $4.4 \mathrm{~nm}$ are achieved by tuning the concentration of filling amount into mesoporous silica. The mesoporous carbon exhibits hexagonal rod-like morphology (a diameter of $\sim 1.2 \mu \mathrm{m}$ ), which confirms that the replication process is highly successful. It is demonstrated that the prepared mesoporous carbon exhibits much higher current density and superior performance as compared to conventional activated charcoal.

\section{Introduction}

Ordered mesoporous carbons have attracted considerable attention in the past few years due to their applications in adsorption of larger molecules, electrochemical double layer capacitor, catalyst support, fuel cells, solar cells, and hydrogen storage systems [1-6]. These kinds of applications require porous carbon with tailored porous structure $[7$, 8]. Recently, several different methods have been developed to synthesize mesoporous carbons. These include the carbonization of polymer aerogels such as resorcinol-formaldehyde resins [9], the catalytic activation of carbon precursors in the presence of metals and organometallic compounds $[10,11]$, and carbonization of polymer blends with thermally unstable components $[12,13]$. However, these methods result in having a mesoporous carbon with broad pore size distribution. Among them, template synthesis method [14-17] has been extensively used due to the obtained material possessing uniform and interconnected pores. The synthesis technique is known as "nanocasting." This synthetic technique involves impregnation of silica template with an appropriate carbon source, carbonization of carbon precursor, and subsequent removal of silica. The resulting carbons are inverse replicas of ordered mesoporous silicas. Since the first successful synthesis of ordered mesoporous carbon (CMK-1) using MCM-48 [14], various structures have been reported from different silica templates. On the other hand, textural parameters such as surface area, pore volume, and pore diameter are found to be significantly influencing the electrocatalytic activity. In supported materials, mesoporous offers high metal dispersion and stability of nanoparticles. Although tuning the textural properties of mesoporous carbon is important for various catalytic and electrocatalytic studies, the effect of sucrose concentration on tuning the properties of mesoporous carbon material is not addressed yet. In this study, textural properties of mesoporous carbons are tuned by varying the concentration of sucrose. In addition, the electrocatalytic activity of prepared carbon material is investigated.

\section{Experimental}

Ordered mesoporous carbon materials referred to as CSB (carbon from SBA-15) was synthesized by pyrolysis of sucrose inside the mesoporous silica (SBA-15). In a typical 


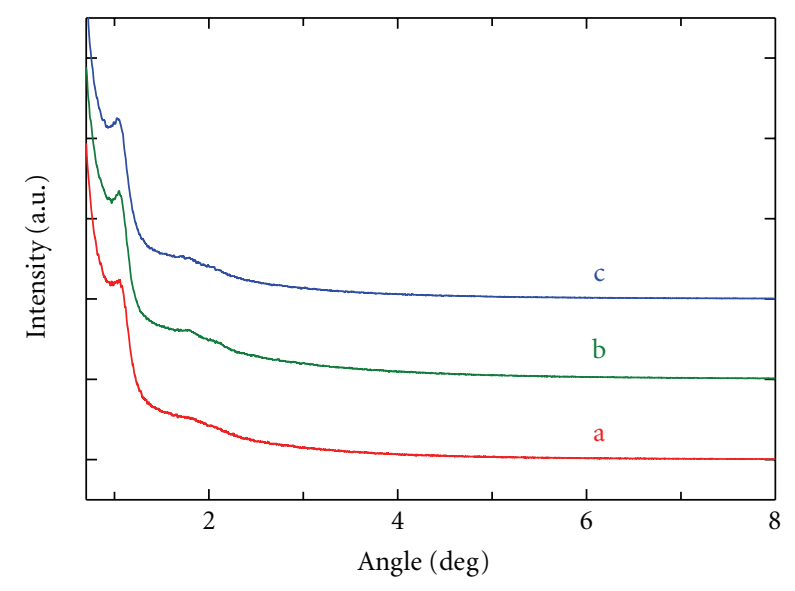

FIgure 1: Powder XRD patterns of CSB materials with different sucrose to water ratios; (a) CSB-1, (b) CSB-2, and (c) CSB-3.

synthesis of mesoporous carbon, $1 \mathrm{~g}$ of SBA- 15 was added to a solution obtained by dissolving $0.7 \mathrm{~g}$ of sucrose and $5.0 \mathrm{~g}$ of water and keeping the mixture in an oven for $6 \mathrm{~h}$ at $100^{\circ} \mathrm{C}$. Subsequently, the oven temperature was raised to $160^{\circ} \mathrm{C}$ for another $6 \mathrm{~h}$. In order to obtain fully polymerized and carbonized sucrose inside the pores of silica template, $0.47 \mathrm{~g}$ of sucrose, $0.05 \mathrm{~g}$ of $\mathrm{H}_{2} \mathrm{SO}_{4}$, and $5.0 \mathrm{~g}$ of water were again added to the pretreated sample and the mixture was again subjected to thermal treatment described above. Carbonization was performed at $900^{\circ} \mathrm{C}$ for $5 \mathrm{~h}$ under $N_{2}$ atmosphere. The resulting carbon/silica composite was treated with HF acid (10 wt.\%) at room temperature to selective removal of silica. The obtained mesoporous carbons are denoted as CSB-1, CSB-2, and CSB-3, which are synthesized using sucrose to water weight ratios of $0.06,0.08$, and 0.12 respectively.

Powder X-ray diffraction patters were obtained through a Rigaku diffractometer using $\mathrm{CuK} \alpha(\lambda=0.15406 \mathrm{~nm})$ radiation, operated at $40 \mathrm{kV}$ and $40 \mathrm{~mA}$ in a step scan mode with narrow divergence slits. $\mathrm{N}_{2}$ adsorption-desorption isotherms were measured at $77 \mathrm{~K}$ on a Micromeritics Tristar II 3020 adsorption analyzer. Before the adsorption measurements, all samples were outgassed at $250^{\circ} \mathrm{C}$ in the port of the adsorption analyzer. The Brunauer-Emmett-Teller (BET) specific surface areas were obtained from adsorption branches in the relative pressure range of $0.05-0.20$. The total pore volume was estimated from the amount of nitrogen gas adsorbed at a relative pressure of 0.98 . The position of the maximum on pore size distribution is referred to as the pore diameter, which was calculated from adsorption branches by Barret-Joyner-Halenda (BJH) method. The HRTEM images were obtained with JEOL JEM-2100F. The preparation of samples for HRTEM analysis involved sonication in ethanol for $5 \mathrm{~min}$ and deposition on a copper grid. The accelerating voltage of the electron beam was $200 \mathrm{kV}$. Hitachi S- $4800 \mathrm{HR}-$ FESEM was used to observe the morphology of the materials prepared at different sucrose to water weight ratios.

Platinum particles supported on mesoporous carbons with loading of $10 \mathrm{wt} \%$ are prepared using $\mathrm{H}_{2} \mathrm{PtCl}_{6} \cdot 6 \mathrm{H} 20$ (Wako chemical, purity: $99.9 \%$ ) as a platinum source. Mes-

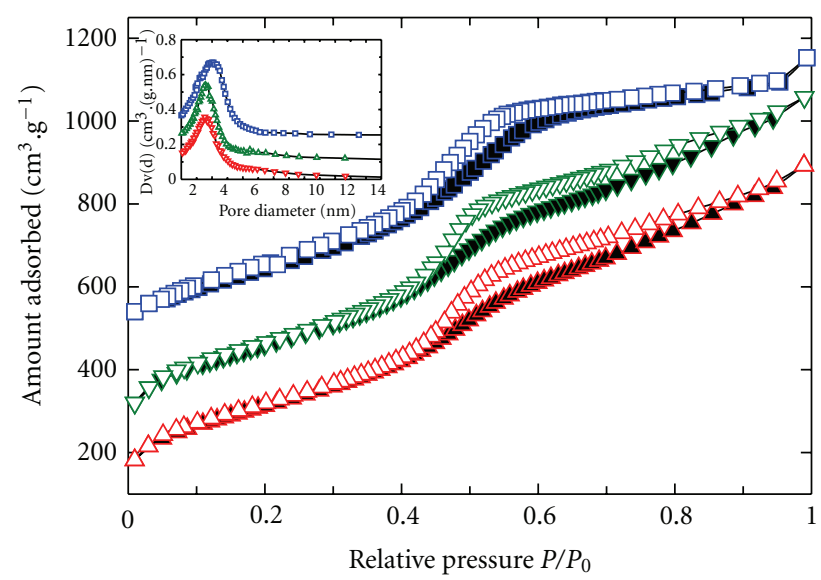

FIGURE 2: Nitrogen adsorption-desorption isotherms of CSB materials with different sucrose to water ratios; $(\Delta)$ CSB-1, $(\nabla)$ CSB-2, and ( $\square$ ) CSB-3.

oporous supports and $\mathrm{Pt}$ particles were dispersed into ethanol. The mixture was dried at room temperature in $\mathrm{N}_{2}$ gas flow. The dried powder was reduced at $400^{\circ} \mathrm{C}$ for $2 \mathrm{~h}$ in a mixed gas $\mathrm{H}_{2}(10 \%)$ and $\mathrm{He}(90 \%)$ flow. The performance of this electrode is compared with that of a $10 \mathrm{wt} \% \mathrm{Pt}$ on activated carbon electrode material. The anode properties of Pt-mesoporous support were examined by ALS/DY2323 bipotentiostat electrochemical analyser. The measurements were carried out in an aqueous solution of $0.5 \mathrm{M} \mathrm{H}_{2} \mathrm{SO}_{4}$. $\mathrm{Pt}$ foil, and $\mathrm{Ag} / \mathrm{AgCl}$ electrode were used as counter and reference electrodes respectively.

\section{Results and Discussion}

The powder X-ray diffraction patterns of mesoporous carbon materials prepared using sucrose as a carbon source at different sucrose to water weight ratio of $0.06,0.08$, and 0.12 are shown in Figure 1. All the samples exhibit sharp distinct reflections of $2 \theta$ below $3.0^{\circ}$, which are characteristic for highly ordered mesostructures belonging to $2 \mathrm{D}$ hexagonal $P 6 \mathrm{~mm}$ space group. The XRD patterns are exactly matched with the patterns of SBA- 15 silica template, which indicates that the mesoporous carbons are inverse replicas of those templates. It is interesting to note that the CSB- 1 also exhibits clear higher-order peaks that can be indexed as (100), (110), and (200) diffractions. The structural order of the CSB-3 material improves when sucrose to water ratio is 0.12 . The unit cell parameters for the mesoporous carbon evaluated from the XRD data are summarized in Table 1. The hexagonal unit cell $a_{0}$ parameter is calculated using the formula $a_{0}=2 \mathrm{~d}_{100} / \sqrt{ } 3$. It is observed that the unit cell constant of these carbon materials increases from 9.7 to $9.9 \mathrm{~nm}$ with increasing the sucrose to water weight ratio in the composition. Subsequently, the pore wall thickness of mesoporous carbon materials also changes which is in the range of 5.3 to $5.5 \mathrm{~nm}$ for all CSB materials.

The mesoporous nature of carbon materials prepared at different sucrose to water ratio is confirmed by nitrogen 
TABLE 1: Textural parameters of CSB materials.

\begin{tabular}{lccccc}
\hline Sample & $a_{0} / \mathrm{nm}$ & $A_{\mathrm{BET}} / \mathrm{m}^{2} \cdot \mathrm{g}^{-1}$ & $V_{p}\left(\mathrm{~cm}^{3} / \mathrm{g}\right)$ & $\mathrm{dp}, \mathrm{BJH}(\mathrm{nm})$ adsorption & Wall thickness $(\mathrm{nm})$ \\
\hline CSB-1 & 9.7 & 1118 & 1.30 & 4.2 & 5.5 \\
CSB-2 & 9.7 & 1286 & 1.39 & 4.4 & 5.3 \\
CSB-3 & 9.9 & 1437 & 1.35 & 4.4 & 5.5 \\
\hline
\end{tabular}

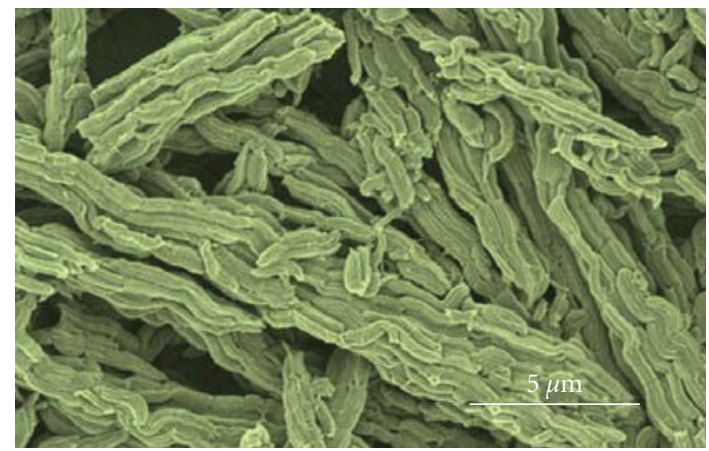

(a)

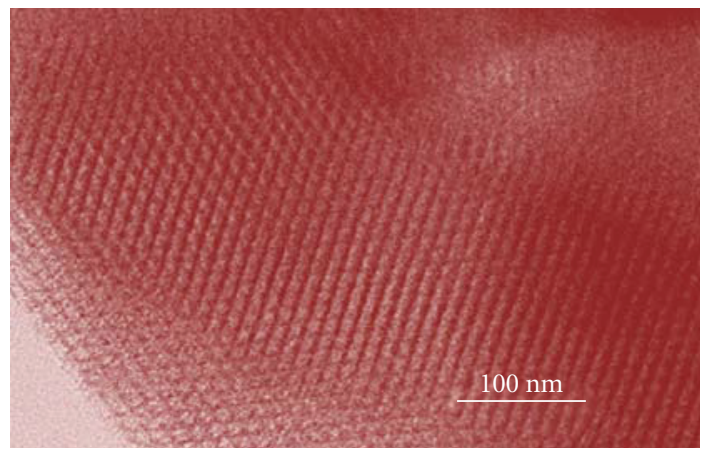

(b)

Figure 3: (a) HR-SEM and (b) HR-TEM images of CSB-3.

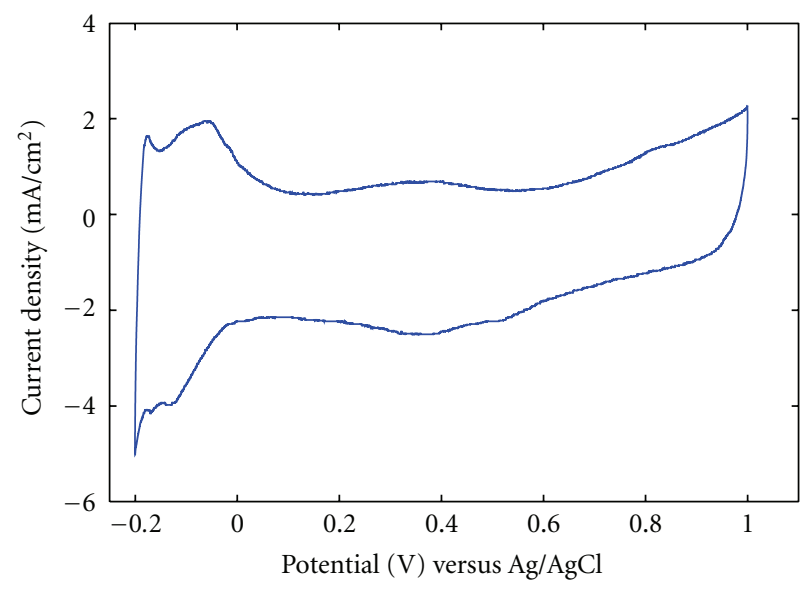

Figure 4: Cyclic voltammogram of $10 \mathrm{wt} \%$ Pt-loaded CSB-3 obtained in $0.5 \mathrm{M} \mathrm{H}_{2} \mathrm{SO}_{4}$ at $50 \mathrm{mVs}^{-1}$.

sorption analysis. Figure 2 shows the nitrogen adsorptiondesorption isotherms of CSB-1, CSB-2, and CSB-3 along with $\mathrm{BJH}$ pore size distribution (inset). All isotherms are of type IV and exhibited a $\mathrm{H}_{2}$ type hysteresis loop. As the relative pressure increases $\left(P / P_{0}>0.4\right)$, all isotherms exhibit a sharp capillary condensation step of nitrogen within uniform mesopores, where the $P / P_{0}$ position of the inflection point is correlated to the diameter of the mesopore. The pore diameter and the specific surface area of the carbon materials gradually increase with increasing sucrose to water weight ratio. The specific surface area for CSB-1 increases from $1118 \mathrm{~m}^{2} / \mathrm{g}$ to $1437 \mathrm{~m}^{2} / \mathrm{g}$ for CSB-3, while the pore diameter also increases from $4.2 \mathrm{~nm}$ to $4.4 \mathrm{~nm}$ for the same samples. The specific surface area and pore diameter are higher for CSB-3 than the other mesoporous carbons prepared using this procedure, which facilitates superior performance in electrochemical cells. It is assumed that the lower sucrose to water ratio used for preparation of CSB-1 material may induce the formation of some amount of disordered carbon such as coke inside the mesochannels, which reduces total surface area. Moreover, the specific pore volume is in the range of 1.30 to $1.39 \mathrm{~cm}^{3} / \mathrm{g}$ for all the prepared carbon materials. Figure 3(a) shows the HR-FESEM images of CSB-3 material confirming rod-like morphology, which is similar to that of silica template. The HR-TEM image of CSB-3 material is shown in Figure 3(b). CSB-3 exhibited highly ordered mesoporous structure with linear array of pores originated from mesoporous silica framework.

Cyclic voltammetry is employed to obtain electrochemical active area of Pt-CSB-3 material. Figure 4 shows the cyclic voltammograms of $10 \mathrm{wt} \% \mathrm{Pt}$-loaded CSB-3 material. The electrochemical active surface area $\left(E_{\mathrm{AS}}\right)$ was calculated using the following equation [18]:

$$
E_{\mathrm{AS}}=\frac{Q_{H}}{[\mathrm{Pt}] \times 0.21},
$$

where $[P t]$ represents the $P t$ loading $\left(\mathrm{mgcm}^{-2}\right)$ in the electrode, $Q_{H}$ represents the charge for hydrogen desorption $\left(\mathrm{mCcm}^{-2}\right)$ and 0.21 represent the charge for the adsorption of $\mathrm{H}_{2}$ monolayer on atomically smooth Pt. It is interesting to note that when using $10 \mathrm{wt} \%$ of Pt loaded on CSB- 3 material, the charge of $\mathrm{H}_{2}$ desorption is higher together with the electrochemical active surface area of Pt being $29 \mathrm{~m}^{2} / \mathrm{g}$ compared to that of $10 \mathrm{wt} \%$ Pt-loaded activated carbon $\left(16 \mathrm{~m}^{2} / \mathrm{g}\right)$. It is observed that the charge of $\mathrm{H}_{2}$ desorption is dependent on active surface area of Pt loaded and textural parameters of carbon materials. Furthermore, platinum-loaded CSB-3 material shows superior performance compared to activated carbon material due to its large ordered pore channels which 
are continuous connected with the large quantity of small pores in the carbon pore walls.

\section{Conclusions}

In summary, the technique used in this study is novel to synthesize ordered mesoporous carbons with high surface areas and large pore diameters by changing sucrose to water weight ratio. It enables to tune the textural properties of mesoporous carbons with uniform pore structure. The mesoporous carbon exhibits surface area of $1437 \mathrm{~m}^{2} / \mathrm{g}$ with ordered pore structure and pore size of $4.4 \mathrm{~nm}$. The results from electrochemical measurements reveal that the high surface area and ordered structure of mesoporous carbon favored superior performance compared with activated carbon.

\section{Acknowledgments}

The author thanks the International Center for Young Scientists (ICYS) and the International Center for Materials Nanoarchitectonics (MANA) at the National Institute for Materials Science, Tsukuba, Japan for financial support.

\section{References}

[1] P. Srinivasu, S. P. Singh, A. Islam, and L. Han, "Metalfree counter electrode for efficient dye-sensitized solar cells through high surface area and large-porous carbon," International Journal of Photoenergy, vol. 2011, Article ID 617439, 2011.

[2] P. Srinivasu, S. P. Singh, A. Islam, and L. Han, "Novel approach for the synthesis of nanocrystalline anatase titania and their photovoltaic application," Advances in Opto Electronics, vol. 2012, Article ID 539382, 2012.

[3] S. H. Joo, S. J. Choi, I. Oh et al., "Ordered nanoporous arrays of carbon supporting high dispersions of platinum nanoparticles," Nature, vol. 412, no. 6843, pp. 169-172, 2001.

[4] L. Schlapbach and A. Züttel, "Hydrogen-storage materials for mobile applications," Nature, vol. 414, no. 6861, pp. 353-358, 2001.

[5] J. Lee, S. Yoon, T. Hyeon, S. M. Oh, and K. B. Kim, "Synthesis of a new mesoporous carbon and its application to electrochemical double-layer capacitors," Chemical Communications, no. 21, pp. 2177-2178, 1999.

[6] K. Kaneko and J. Imai, "Adsorption of NO on activated carbon fibers," Carbon, vol. 27, pp. 954-955, 1989.

[7] K. Xia, Q. Gao, J. Jiang, and J. Hu, "Hierarchical porous carbons with controlled micropores and mesopores for supercapacitor electrode materials," Carbon, vol. 46, no. 13, pp. 1718-1726, 2008.

[8] A. H. Lu, W. Schmidt, B. Spliethoff, and F. Schüth, "Synthesis of ordered mesoporous carbon with bimodal pore system and high pore volume," Advanced Materials, vol. 15, no. 19, pp. 1602-1606, 2003.

[9] H. Tamon, H. Ishizaka, T. Araki, and M. Okazaki, "Control of mesoporous structure of organic and carbon aerogels," Carbon, vol. 36, no. 9, pp. 1257-1262, 1998.

[10] H. Tamai, T. Kakii, Y. Hirota, T. Kumamoto, and H. Yasuda, "Synthesis of extremely large mesoporous activated carbon and its unique adsorption for giant molecules," Chemistry of
Materials, vol. 8, no. 2, pp. 454-462, 1996.

[11] B. Rand and H. Marsh, "The process of activation of carbons by gasification with $\mathrm{CO}_{2}$-III. Uniformity of gasification," Carbon, vol. 9, no. 1, pp. 79-85, 1971.

[12] J. Ozaki, N. Endo, W. Ohizumi et al., "Novel preparation method for the production of mesoporous carbon fiber from a polymer blend," Carbon, vol. 35, no. 7, pp. 1031-1033, 1997.

[13] N. Patel, K. Okabe, and A. Oya, "Designing carbon materials with unique shapes using polymer blending and coating techniques," Carbon, vol. 40, no. 3, pp. 315-320, 2002.

[14] R. Ryoo, S. H. Joo, and S. Jun, "Synthesis of highly ordered carbon molecular sieves via template-mediated structural transformation," Journal of Physical Chemistry B, vol. 103, no. 37, pp. 7745-7746, 1999.

[15] C. Liang, Z. Li, and S. Dai, "Mesoporous carbon materials: synthesis and modification," Angewandte Chemie-International Edition, vol. 47, no. 20, pp. 3696-3717, 2008.

[16] J. S. Lee, S. H. Joo, and R. Ryoo, "Synthesis of mesoporous silicas of controlled pore wall thickness and their replication to ordered nanoporous carbons with various pore diameters," Journal of the American Chemical Society, vol. 124, no. 7, pp. 1156-1157, 2002.

[17] H. I. Lee, J. H. Kim, D. J. You et al., "Rational synthesis pathway for ordered mesoporous carbon with controllable 30- To 100angstrom pores," Advanced Materials, vol. 20, no. 4, pp. $757-$ 762, 2008.

[18] A. Pozio, M. De Francesco, A. Cemmi, F. Cardellini, and L. Giorgi, "Comparison of high surface $\mathrm{Pt} / \mathrm{C}$ catalysts by cyclic voltammetry," Journal of Power Sources, vol. 105, no. 1, pp. 1319, 2002. 

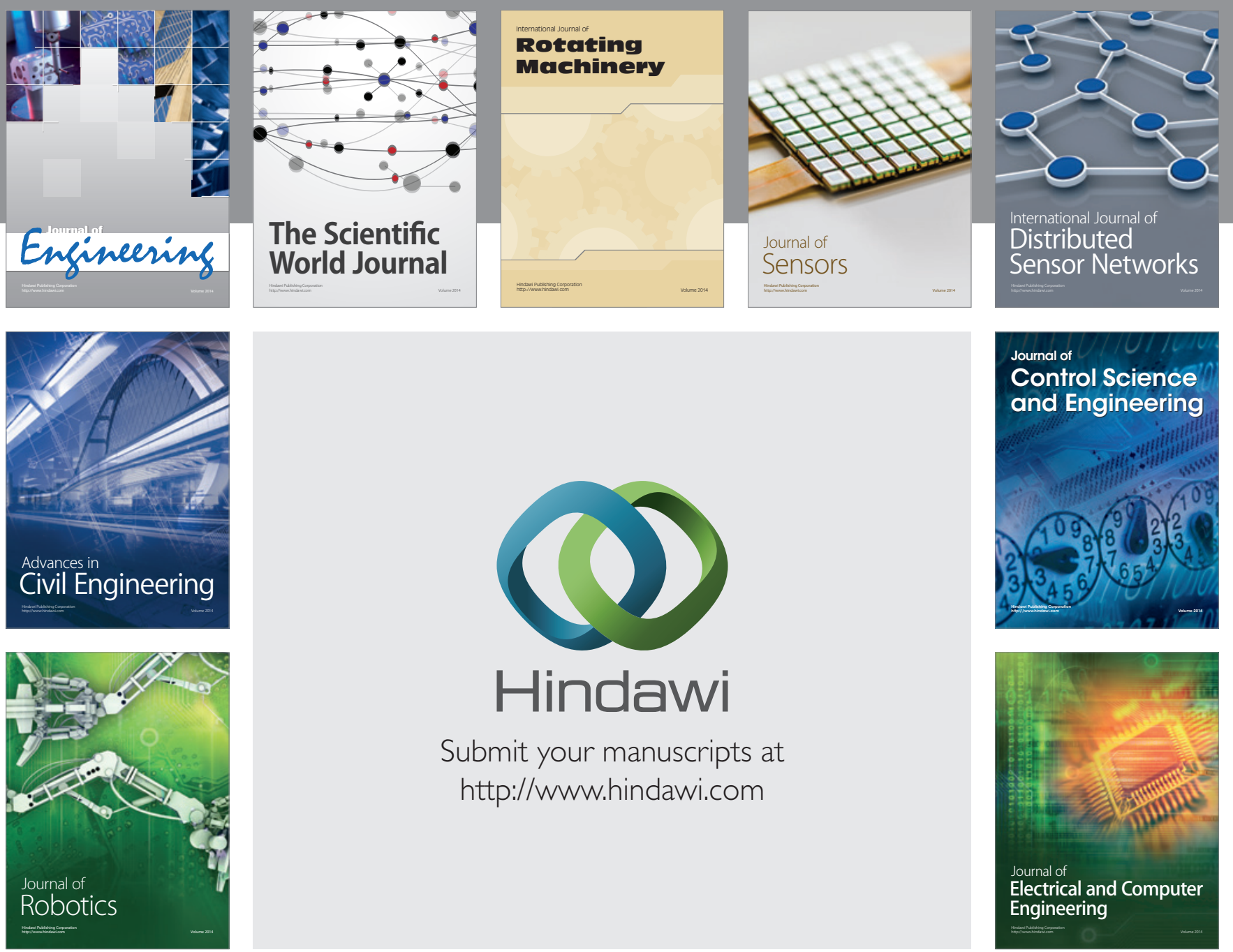

Submit your manuscripts at

http://www.hindawi.com
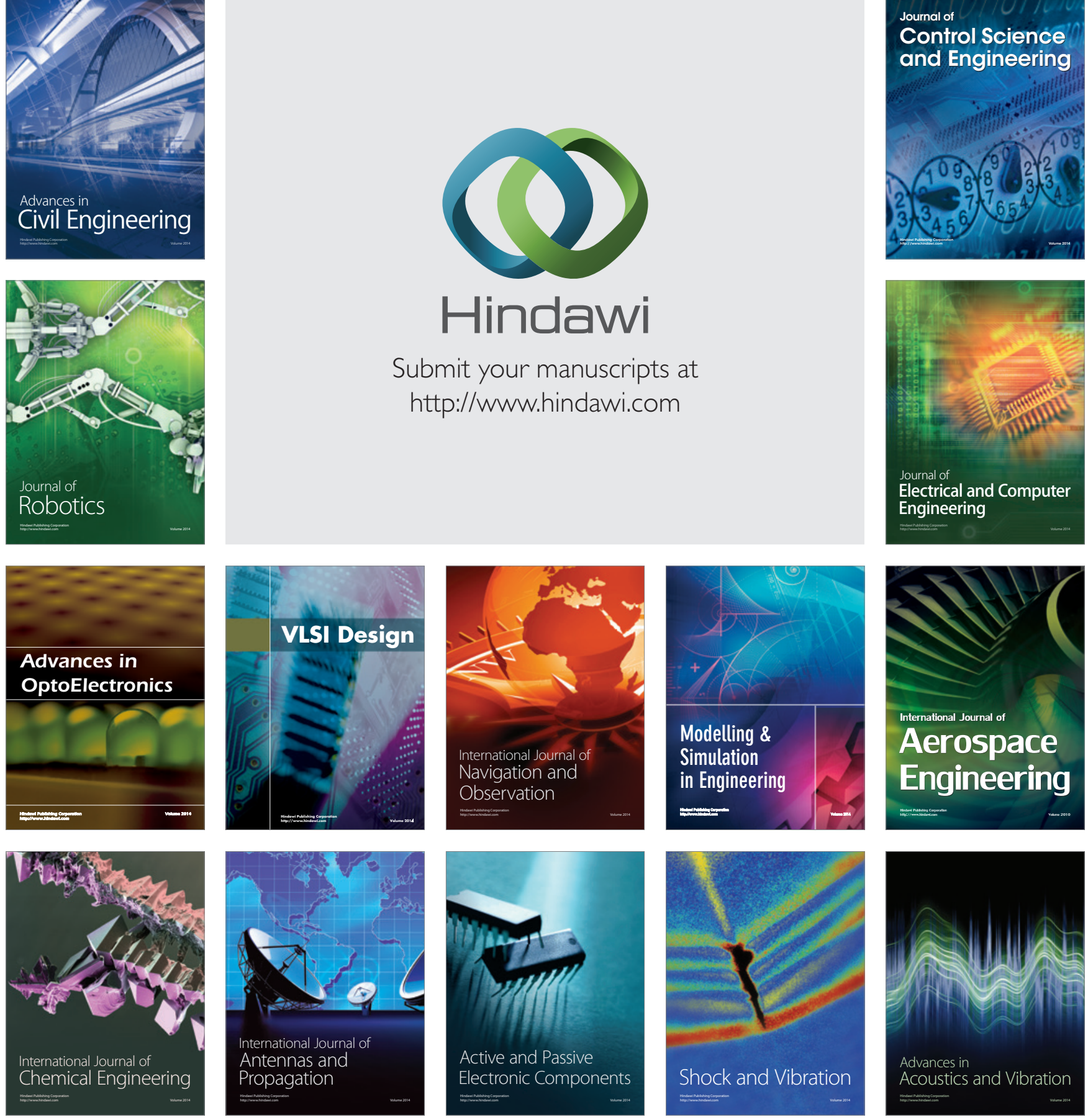